\title{
Evaluación de Ozonoterapia en Dermatopatía Generalizada en Perros
}

María Verónica Rodríguez Jordan, Consultorio Veterinario "Bocca De Cannes" Jorge Washington Tobar Vera, Docente de la Universidad Técnica de Babahoyo Víctor Manuel De La Cruz Cañar Díaz, Especialista de la universidad Técnica de Babahoyo

Gustavo Adolfo Navarrete Suarez, Docente de la Universidad técnica de Manabí

Doi: 10.19044/esj.2019.v15n6p364 URL:http://dx.doi.org/10.19044/esj.2019.v15n6p364

\section{Resumen}

Se realizó un estudio experimental en 30 perros con dermatopatías generalizadas en el consultorio veterinario Bocca de Cannes en la ciudad de Guayaquil. El objetivo fue evaluar la rapidez de la ozonoterapia en la remisión de las dermatopatías generalizadas así como también caracterizar las dermatopatías en función de la causa y severidad en perros. Se evaluó la eficacia de dicho tratamiento según tres esquemas de ozonoterapia para así relacionar con las variables independientes edad, sexo, raza y tipo de lesión. El tiempo promedio para evaluar la remisión es a los 21 días. Se pudo determinar que con la ozonoterapia se logró aumentar la velocidad de remisión de las lesiones, reduciendo el número de días de curación. Por los resultados de esta experiencia nos permitimos recomendar el uso de ozonoterapia para dermatopatías generalizadas en perros, sean éstas superficiales o profundas.

Palabras claves: Ozonoterapia, dermatopatías, remisión, lesiones 


\title{
Evaluation of Ozone Theraphy in Generalized Dermatopathy in Dogs
}

\author{
María Verónica Rodríguez Jordan,
} Consultorio Veterinario "Bocca De Cannes"

Jorge Washington Tobar Vera, Docente de la Universidad Técnica de Babahoyo

Víctor Manuel De La Cruz Cañar Díaz, Especialista de la universidad Técnica de Babahoyo

Gustavo Adolfo Navarrete Suarez,

Docente de la Universidad técnica de Manabí

\begin{abstract}
An experimental study was performed on $30 \mathrm{dogs}$ with generalized dermatopathies at the Bocca Veterinary Clinic of Cannes in the city of Guayaquil. This paper focuses on evaluating the rapidity of ozone therapy in the remission of generalized dermatopathies. The dermatopathies which is based on the function of the cause and severity in dogs was characterized. It was used to evaluate the effectiveness according to three ozone therapy schemes that are related to the independent variables: age, sex, race and type of injury. The average time to evaluate remission is 21 days. Hence, we were able to establish the fact that with the ozone therapy, the rate of remission of the lesions increases, thereby reducing the number of days of healing. From the results of this study, we hereby recommend the use of ozone therapy for generalized dermatopathies in dogs, whether superficial or deep.
\end{abstract}

Keywords: Ozone therapy, dermatopathies, remission, injuries

\section{Introduction}

La importancia de utilizar nuevos métodos terapéuticos en Medicina Veterinaria radica en que es indispensable obtener actualizaciones con resultados positivos, exitosos, medibles y estadísticos en farmacoterapia. Actualmente existen métodos terapéuticos que no emplean fármacos como: Fisioterapia, acupuntura, hidroterapia, entre otros.

La aplicación de la mezcla de ozono y oxígeno conocido como Ozonoterapia se identifica como un método que permite aplicar una solución cualitativamente innovadora a tratamientos dermatológicos, en vista de que muchos tratamientos convencionales demandan de tiempo y recuperaciones 
muy pasivas y a largo plazo con resultados fármaco-resistentes posteriormente.

El ozono (O3) es un gas alótropo de oxígeno. A temperatura y presión normal es un gas inestable que se descompone rápidamente para volver a su molécula de oxígeno (O2). Debido a esta característica no se puede almacenar o envasar en un recipiente, sino que debe generarse en el lugar y utilizarse inmediatamente. La ozonización se elige generalmente cuando se necesita su propiedad más importante: su gran potencial de oxidación que le permite eliminar los compuestos orgánicos que le dan al agua un color, olor y sabor desagradable, y al mismo tiempo para desactivar agentes patógenos en el agua. Otro importante aspecto característico de la ozonización es la ausencia de un efecto residual (IOA, 2016).

En la ciudad de Guayaquil los casos positivos de dermatitis en perros, aumentan constantey significativamente debido a déficits nutricionales, alérgicos, climatizaciones, infecciones por bacterias, parásitos y hongos. Los casos clínicos dermatológicos se manifiestan de diferentes maneras y a través de diversas lesiones y con una historia clínica adecuada acompañada de un plan diagnóstico definitivo se puede obtener a largo plazo un tratamiento final.

Por tal motivo, la Ozonoterapia es una opción cualitativa, innovadora, aplicable en algunos problemas terapéuticos en diversas enfermedades.

La ozonoterapia es una herramienta terapéutica simple y accesible para restablecer la salud de nuestros pacientes en Medicina Veterinaria. A través de este estudio se demostrarán los resultados de la aplicación de dicho tratamiento, los cuales se traducen en una pronta recuperación permitiendo seguir con el tratamiento por la baja inversión en corto tiempo y obteniendo así una un nivel óptomo de salud en la mascota.

La Medicina Veterinaria en Ecuador constantemente ha innovado e implementado diferentes alternativas terapéuticas para el bienestar y salud de las mascotas, motivo por el cual es fundamental incluir una opción de Ozonoterapia en el tratamiento de problemas de piel incentivando y dando a conocer este tratamiento a nuestros colegas.

En otras palabras, la mezcla de ozono y oxígeno es una terapia que demostrará los resultados que las terapias comunes y convencionales hasta ahora tardan en demostrar en lo que respecta a la mejoría de los problemas dermatológicos.

\section{Objetivos}

Objetivos Generales

Determinar laevaluación de ozonoterapia en dermatopatías generalizadas en los perros que lleguen al Consultorio Veterinario Bocca de Cannes en la Ciudad de Guayaquil. 


\section{Objetivos Específicos}

Caracterizar las dermatopatías en función de la causa y severidad en perros. Evaluar la eficacia según tres esquemas de ozonoterapia. Relacionar con variables independientes: edad, sexo, raza y tipo de lesión.

\section{Generalidades}

En la actualidad uno de los principales obstáculos para la amplia aceptación de la ozonoterapia es el desconocimiento. Sin fundamento científico algunos afirman que el ozono es tóxico en cualquier aplicación, olvidando que todo depende de la dosis aplicada como en el caso de cualquier otra sustancia. Utilizando las dosis apropiadas, el ozono activa mecanismos antioxidantes que protegen al organismo de radicales libres, los cuales son los responsables del envejecimiento y de la mayoría de las patologías (Scwhartz \& Martínez, 2012).

El ozono como tal es una sustancia cuya molécula está compuesta por tres átomos de oxígeno, formada al disociarse los dos átomos que componen el gas. El ozono tiene un importante uso industrial como precursor en la síntesis de algunos compuestos orgánicos, además de depurador y como antioxidante (Jiménez, 2010).

Se encuentra en pequeñas cantidades en la estratósfera formando la capa de ozono, la cual se forma por la radiación ultravioleta que disocia a las moléculas de oxígeno $(\mathrm{O} 2)$ que pueden reaccionar con otra molécula de $\mathrm{O} 2$ y formar ozono. A su vez hay un equilibrio porque éste es destruido por la radiación UV y actúa como filtro para que la radiación no traspase a la superficie de la tierra. El ozono en la atmósfera se encuentra en aproximadamente 20 partes por mil millones (ppmm) (Tecnozono, 2015).

En el ámbito ambiental fue muy importante el momento en que fue descubierto en 1985 un agujero en la capa de ozono antártico por confirmación científica. A raíz de esto se impulsó a tomar medidas para proteger la capa de ozono, creando en 1987 el Protocolo de Montreal firmado por 28 países, en el cual se prohibían sustancias que dañaran la capa de ozono (www.un.org, 2000).

A pesar de tener la desventaja de ser inestable, el ozono tiene igualmente un poder germicida alto, razón por la cual este tiene múltiples beneficios en diferentes tipos de dermatitis y en varios procesos infecciosos (Martínez, Re \& Pérez, 2012).

Las principales dermatopatías que presentan los caninos son los piodermas de superficie (dermatitis piotraumática, intertrigo) y los piodermas superficiales (Fogel \& Manzuc, 2009). Estas se presentan a partir de los 3 meses de edad, siendo la edad un factor principal en estas afecciones caninas. Otro de los factores más conocidos en estas enfermedades es la raza. En ciertas razas las dermopatías se presentan con mayor frecuencia; por ejemplo, existe 
una dermatosis que responde al zinc en el Husky siberiano, en razas de pelo corto existen ciertos tipos de foliculitis, el acné se presenta en el bóxer, gran danés, bulldog. El ovejero inglés sufre con más frecuencia de piodermias profundas.

Las dermopatías son causadas generalmente por el Staphylococcus intermedius y se limita a los perros, el Staphylococcus schleiferi, es una bacteria nueva en infecciones crónicas y que se han expuesto a antibióticos (Medleau \& Hnilica, 2007).

Afectan la capa córnea y anexos. En este grupo tenemos el intertrigo, el sobrecimiento bacteriano, impétigo, las foliculitis, piodermas de las uniones mucocutáneas (Machicote, 2011).

Trastorno por trauma autoinducido, debido a mordidas, por rascado o por frotar con el fin de aliviar la picazón o el dolor. También llamada dermatitis aguda húmeda, "hot spot" o "parche caliente" (Balazs, 2012).

\section{Metodología}

La investigación se realizó en el Consultorio Veterinario Bocca de Cannes en la Ciudad de Guayaquil en los perros que llegaron a la consulta presentando dermatopatías. La ciudad de Guayaquil tiene las siguientes coordenadas: latitud y longitud de $02^{\circ} 15^{\prime} \mathrm{S}$ y $79^{\circ} 52^{\prime} \mathrm{W}$. (mapsofworld.com). La investigación fue realizada en el lapso de un mes con 30 pacientes.

\section{Métodos}

El tipo de método con el que se realizó en esta investigación fue experimental, esto con el propósito de evaluar la utilidad de la evaluación de la ozonoterapia en las dermatopatías generalizadas en perros.Se realizó en todos los perros con problemas dermatológicos generalizados que acudieron a la consulta. Se instauró el tratamiento con el gas ozono con el fin de probar su efectividad. Los perros del estudio debieron estar afectados con dermatopatías previamente diagnosticadas por medio de exámenes complementarios para conocer las causales. Luego de esto se procedió a la aplicación del ozono por gasificación externa. En un período de 7, 15 y 21 días se evaluó su eficacia. Se midieron, si hubiera, la disminución en las medidas de las lesiones generalizadas presentadas. Se realizó la respectiva anamnesis y se elaboraron fichas clínicas donde se registró: raza, tipo de lesión, el día de evaluación, el tiempo de aplicación, y esquema de ozonoterapia, Se observó si hubo mejoría de las lesiones y de las zonas afectadas.

\section{Materiales y Equipos}

Se utilizaron los siguientes materiales: muestras, bozales, mascarillas, guantes, gasas, máquina de peluquería, bisturí, placas portaobjetos, fundas, 
mesa de exploración, aceite ozonizado, bañeras, mandil, fichas clínicas, bolígrafos.

\section{Equipos}

Se utilizaron los siguientes equipos: generador de ozono, sistema de oxigenación para piel, tanque de oxígeno, computadora, impresora, microscopio y cámara fotográfica.

\section{$\underline{\text { Procedimiento }}$}

A los perros afectados se les procedió a realizar los baños o aplicación directa de ozono en el día inicial, al día 7 se midieron los parámetros de la extensión de las lesiones, y luego a los 21 días. Todas las remisiones se registraron con fotografías tomadas, como el antes y después del tratamiento con ozono. En este estudio se evaluó la efectividad de la ozonoterapia en las dermatopatías generalizadas.

Para evaluar si existió disminución de las lesiones se tomó en cuenta los resultados de citologías negativos al cabo de 21 días post tratamiento.

\section{Protocolo Del Proceso De Ozonización}

Se realizó la aplicación mediante la ozonoterapia por bolsa plástica/o baños de inmersión y de forma directa. Se aplicó el ozono directamente; la ozonización por bolsa debió rodear la o las superficies a tratar y se procedió a insuflar dentro de la bolsa el ozono. La ozonización por inmersión se realizó por baños.

En todas las técnicas de ozonización antes mencionadas se utilizó una concentración de $60 \mathrm{ug}$, durante 10/15 o 25 minutos.

\section{Toma De Muestras}

Las tomas de la muestras de los perros con dermatopatías se realizaron antes del tratamiento con ozono. El examen de diagnóstico para las dermatopatías fue complementario al uso del microscopio o cultivo de piel. La eficacia de la ozonoterapia se midió por la remisión o la disminución de las lesiones presentadas en los perros a los 7 y 21 días post tratamiento.

\section{Resultados}

Caracterización de las Dermatopatías en Función de la Causa y Severidad en Perros

En el presente trabajo se muestrearon 30 perros de edades de entre 2 meses hasta 11 años que acudieron a la consulta por presentar dermatopatías generalizadas y fueron tratados con ozonoterapia. Se caracterizó las dermatopatías en función de la causa y se pudo encontrar que las causas fueron 
bacterias y ácaros. También se las clasificó como mixtas a aquellas que eran una combinación de bacterias más ácaros como se indica en la Tabla 1.

\section{Dermatopatías por bacterias}

Las bacterias causantes de las dermatopatías fueron Staphyloccous spp 26,6\%, Staphylococcus epidermidis 33,3\%, Proteus spp 13,3\%, Escherichia Coli 13,3\%, Staphylococcus aureus 6,6\%, Klelbsiella 3,3\%, Enterococcus $3,3 \%$.

Tabla 1. Dermatopatias causadas por bacterias

\begin{tabular}{ccc}
\hline BACTERIAS & $\mathrm{N}^{0}$ & $\%$ \\
\hline Escherichia Coli & 4 & 13.33 \\
Staphylococcus spp & 8 & 26.66 \\
Proteus spp & 4 & 13.33 \\
Staphylococcus aureus & 2 & 6.66 \\
Klebsiella spp & 1 & 3.33 \\
Enterococcus & 1 & 3.33 \\
Staphylococcus epidermidis & 10 & 33.33 \\
Total & 30 & 100 \\
& & \\
\hline
\end{tabular}

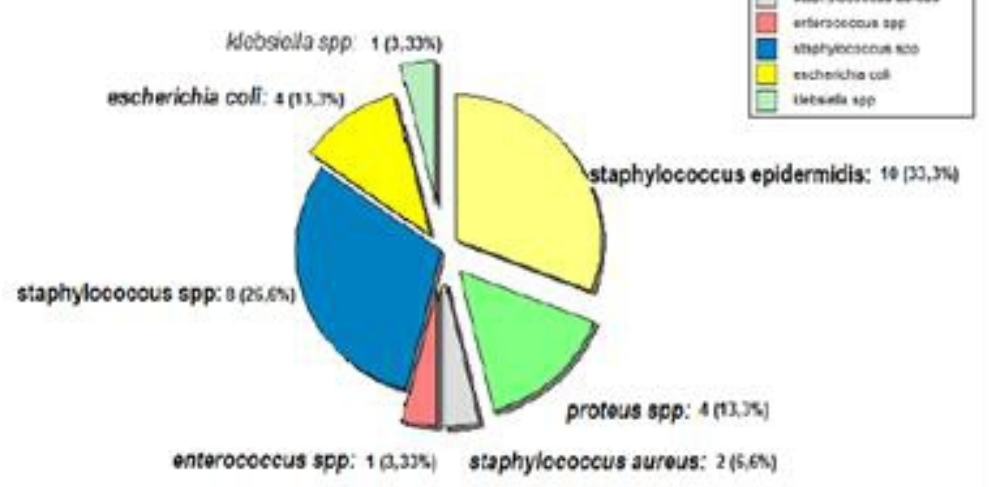

Gráfico 1. Representación gráfica de distribución de dermatopatias por bacterias

Dermatopatías por ácaros

Los ácaros estuvieron distribuidos de la siguiente manera: un 96\% de las dermopatías fueron ocasionadas por Demodex canis y un $4 \%$ por Sarcoptes 
scabiei. Cabe recalcar que todas las lesiones fueron mixtas; es decir, se encontrabó más de un agente causal.

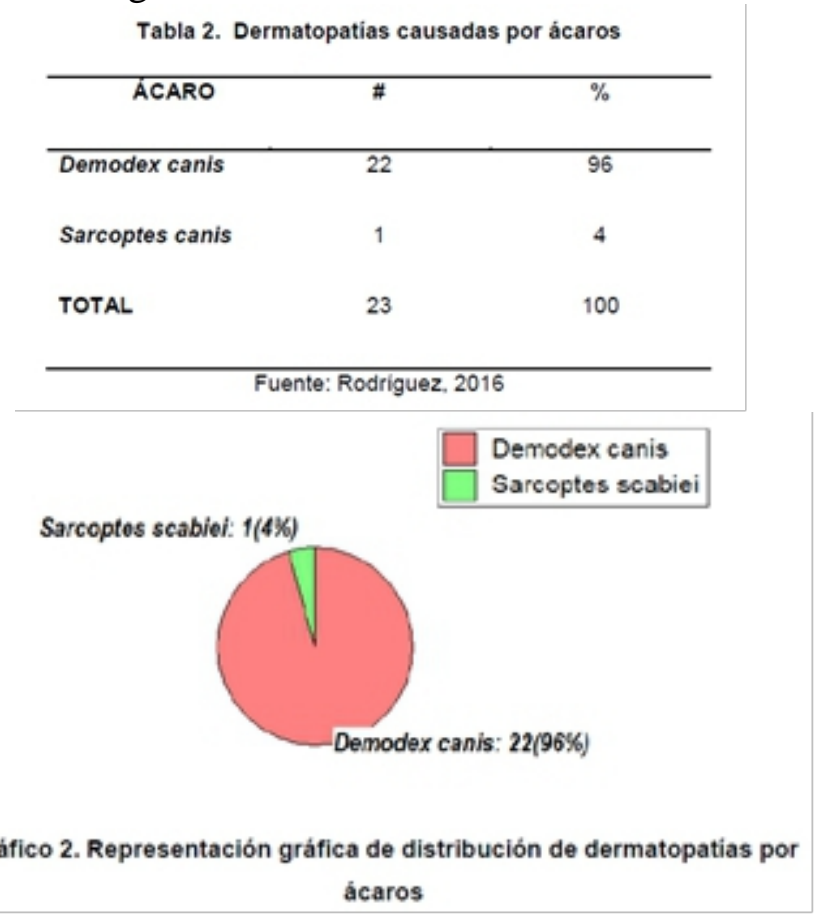

Tipo de dermatopatías mixtas y bacterianas

Las dermatopatías mixtas afectaron en un $77 \%$ de los casos y el resto fueron producidas por bacterias en un $23 \%$.

Tabla 3. Dermatopatias mixtas y bacterianas

\begin{tabular}{lcc}
\hline \multicolumn{1}{c}{ MIXTA } & $\#$ & $\%$ \\
\hline $\begin{array}{l}\text { ÁCARO Y } \\
\text { BACTERIA }\end{array}$ & 23 & 77 \\
BACTERIANA & 7 & 23 \\
TOTAL & 30 & 100 \\
\hline
\end{tabular}

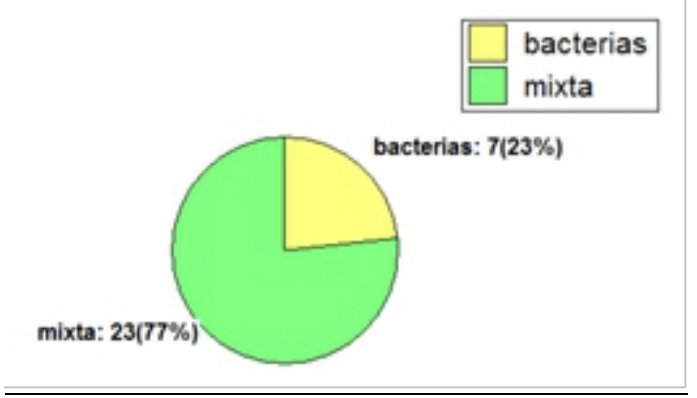




\section{Dermatopatías en función de la severidad}

Las dermatopatías fueron clasificadas en superficiales y profundas, y se encontró que las dermatopatías mixtas y superficiales se presentaron en un $82,6 \%$ de los casos y las profundas en un 17,39\%. El $100 \%$ de las dermatopatías bacterianas fueron superficiales.

Tabla 4. Distribución de las dermatopatias por severidad de las lesiones

\begin{tabular}{ccccc}
\hline $\begin{array}{c}\text { Clasificación en } \\
\text { función de la causa }\end{array}$ & Superficiales & Profundas & Total \\
\hline & $N^{\circ}$ & $\%$ & $N^{\circ}$ & \\
Mixtas & $19 / 23$ & 82,6 & $4 / 23$ & $23 / 100$ \\
Bacterianas & $7 / 7$ & 100 & $0 / 7$ & $7 / 100$ \\
Total & & & & $30 / 100$ \\
\hline
\end{tabular}

Evaluación de los Tres Esquemas de Ozonoterapia

La ozonoterapia fue administrada en los dos tipos de clasificación de la dermatopatía. No hubo complicaciones en ninguno de los casos estudiados.

\section{Evaluación del esquema tópico}

Se realizó la aplicación mediante la ozonoterapia por aplicación tópica. Se realizó en 7 pacientes lo que representó el 23\%. La tolerancia del esquema en general fue buena en un $96 \%$.

Gráfico 4. Representación gráfica de Esquema de ozonoterapia

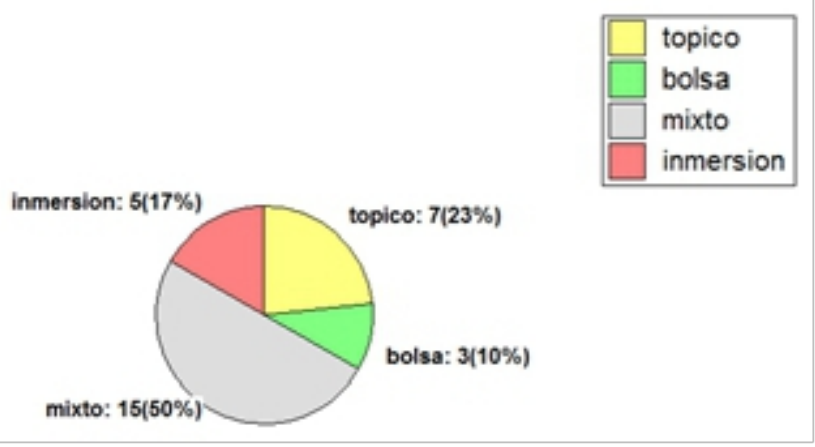

2. Esquema por inmersión

La ozonización por inmersión se realizó por baños y fue tolerable en todos los casos; fue realizada en el 17\% de los casos. 


\section{Esquema por bolsa}

Durante la ozonización por bolsa se debió rodear la o las superficies a tratar y se procedió a insuflar dentro de la bolsa el ozono. Se realizó en el 10\% de los casos, habiendo un caso en el que su tolerancia no fue muy buena, el cual representa un $3 \%$.

\section{Evaluación final}

Se encontró que en el $20 \%$ de las dermatopatías mixta se realizó tratamiento tópico, en el 3,3\% de los casos por medio de bolsa, $10 \%$ por inmersión y un $43,3 \%$ fue mixta.

En el caso de la ozonización para las dermatopatías bacterianas un $57,1 \%$ fue tópica, un $14,2 \%$ por medio de bolsa, un $14,2 \%$ por inmersión y en el $14,2 \%$ de los casos fue mixta.

Tabla 5. Eficacia en el tratamiento impartido

\begin{tabular}{|c|c|c|c|c|c|c|c|c|c|}
\hline \multirow[b]{2}{*}{ Dermatopatia } & \multicolumn{2}{|c|}{ Tópico } & \multicolumn{2}{|c|}{ Bolsa } & \multicolumn{2}{|c|}{ Inmersión } & \multicolumn{2}{|c|}{ Mixta } & \multirow[t]{2}{*}{ Total } \\
\hline & $\mathrm{n}$ & $\%$ & $\mathbf{n}$ & $\%$ & $\mathrm{n}$ & $\%$ & $\mathrm{n}$ & $\%$ & \\
\hline Mixta & 6 & 20 & 1 & 3,3 & 3 & 10 & 13 & 43,3 & $23 / 100$ \\
\hline Bacteriana & 4 & 57,1 & 1 & 14,2 & 1 & 14,2 & 1 & 14,2 & $7 / 100$ \\
\hline
\end{tabular}

Como promedio, los pacientes acudieron a los 21 días de su control después de la inclusión en el estudio y tuvieron remisión de sus lesiones. El $100 \%$ de los pacientes (30) utilizaron ozonoterapia en la forma planteada, es decir, en baños de inmersión, bolsa plástica o forma tópica. Ninguno de los pacientes tuvo intenciones de dejar el tratamiento, al menos en los días en que se realizó.

\begin{tabular}{lccc}
\hline ESQUEMA & & \multicolumn{2}{c}{ DIAS } \\
\cline { 2 - 4 } & 7 dias & 15 dias & 21 dias \\
Tópica & Remisión & Remisión & Remisión \\
Inmersión & Intermedio & Remisión & Remisión \\
\hline Bolsa & Intermedio & Intermedio & Intermedio \\
Mixta & Intermedio & Remisión & Remisión \\
\hline
\end{tabular}

\section{Evolución de los síntomas}

En los 30 pacientes, la terapia de ozono fue realizada completamente y antes de ello se tomaron muestras de piel para realizar exámenes 
citológicos. La evaluación de los casos fue obtenida por examen clínico y examen de laboratorio. Los resultados son expuestos en la siguiente tabla:

\begin{tabular}{llllllllll}
\hline & $\begin{array}{l}\mathrm{N}^{\circ} \\
\text { casos }\end{array}$ & & Desaparece & Disminuye & Cambios & Agravación \\
\hline Lesiones & 30 & 12 & $40 \%$ & 1 & $3,3 \%$ & 17 & $56,6 \%$ & 0 & $0 \%$ \\
\hline
\end{tabular}

La actividad antimicrobiana de la ozonoterapia es evidente. De acuerdo a los reportes de los pacientes un56,6\% presentó mejorías, en un 40\% de los casos desaparecieron sus lesiones, en el 3,3\% de los casos se disminuyó, y no hubo pacientes que se agravaran. Los resultados obtenidos en ese campo están claramente asociados a la acción antiinflamatoria de la ozonoterapia junto con su acción antinfecciosa. En otras palabras,, la eficacia del ozono en los casos de dermatopatías fue más que evidente.

\section{$\underline{\text { Tolerancia }}$}

La ozonoterapia pudo ser evaluada a partir de los 30 casos; esto es el total de los casos en los que se utilizó la técnica de manera exclusiva Esta tolerancia fue apreciada siguiendo una clasificación de buena, regular o mala, con los siguientes resultados:

Buena; 29 casos $(96,6 \%)$

Regular: 0 casos $(0 \%)$

Mala: 1 caso $(3,3 \%)$

Como dato general de los pacientes se reportó repetidamente alivio, aroma agradable, buena tolerancia, menos prurito y la irritación disminuyó.

Al final de este estudio se concluye que la ozonoterapia puede ser utilizada amplia y cotidianamente en el tratamiento de las dermatopatías generalizadas en perros, demostrando excelente tolerabilidad y además aceptación de los resultados obtenidos.

Relacionar Con Variables Independientes Edad, Sexo, Raza y Tipo de Lesión

\section{Variable por edad}

La muestra se distribuyó en grupos menores de un año y mayores de un año, y se encontró que en un 43,5\% fueron menores de 1 año Y un 56,5\% fueron los mayores de 1 año . Divididas en grupos de mixtas y bacterianas, se encontró que en el grupo de cachorros un 6,6\% de las dermatopatías eran bacterianas y $36,6 \%$ mixtas. 
Variable por sexo

La muestra se distribuyó en hembras y machos, y se encontró que un $39,9 \%$ de los casos fueron hembrasy un $59,9 \%$ machos.

Variable por tipo de pelo

La muestra se distribuyó en perros de pelo corto (33\%) y de pelo largo $(67 \%)$.

\begin{tabular}{|c|c|c|c|c|c|c|c|c|}
\hline \multirow[t]{2}{*}{ Variable } & \multicolumn{2}{|c|}{ Mixtas } & \multicolumn{2}{|c|}{ Bacterias } & \multicolumn{4}{|c|}{ Tratamiento } \\
\hline & $\mathrm{N}$ & $\%$ & $\mathrm{~N}$ & $\%$ & $B$ & $T$ & $T$ & $M$ \\
\hline \multicolumn{9}{|l|}{ Edad } \\
\hline $\begin{array}{c}\text { Menores de } \\
1 \text { anio }\end{array}$ & $11 / 30$ & 36,6 & $2 / 30$ & 6,6 & & $\mathrm{x}$ & $x$ & $x$ \\
\hline $\begin{array}{c}\text { Mayores de } \\
1 \text { ahio }\end{array}$ & $12 / 30$ & 39,9 & $5 / 30$ & 16,6 & & $x$ & & $x$ \\
\hline \multicolumn{9}{|l|}{ Sexo } \\
\hline Macho & $13 / 30$ & 43,3 & $5 / 30$ & 16,6 & $x$ & $x$ & $x$ & $x$ \\
\hline Hembra & $10 / 30$ & 33,3 & 230 & 6,6 & $x$ & $\mathrm{x}$ & $x$ & \\
\hline \multicolumn{9}{|l|}{ Tipo de pelo } \\
\hline Pelo corto & $15 / 30$ & 50 & $5 / 30$ & 16,6 & & $x$ & $x$ & $x$ \\
\hline Pelo largo & $7 / 30$ & 23,3 & $3 / 30$ & 10 & $x$ & $x$ & $x$ & $x$ \\
\hline
\end{tabular}

\section{Discusión}

En la tesis publicada por Pacheco Albán (2012) este menciona que hubo a los 21 días de tratamiento una mejoría al 100\% de las lesiones en otitis externas causadas por diferentes microorganismos. En dichapublicación la mejoría encontrada en los 29 casos fue buena con el 96,6\%.

Ramírez (2015) menciona los beneficios terapéuticos que brinda, ya sea administrado por vía gaseosa o por medio del agua o en base de aceite. Lo que demostramos en el presente estudio es que el ozono posee una amplia aceptación y tolerancia en nuestros pacientes sea cual sea la forma de aplicación. 
Según Scwhartz y Martínez Sánchez (2012) la acción de reparación del ozono sobre la pared de los vasos sanguíneos, se estudió en un ensayo clínico aleatorizado publicado por el "European Journal of Pharmacology en el año 2005 ”, donde se reportó la recuperación de úlceras en pacientes diabéticos. Se demostró además que el ozono actúa a nivel de un elemento conocido como óxido nítrico; esta sustancia actúa a nivel de los vasos sanguíneos favoreciendo la vasodilatación y por esta razón aumenta el flujo sanguíneo en los órganos. Estodemuestra los beneficios del ozono en problemas dermatológicos de múltiple etiología.

La acción del ozono como agente antioxidante fue comprobada en un estudio realizado por (Bicer \& Otros, 2016), quienes indicaban que la aplicación tópica de ozono proporciona una mejora en la cicatrización de la dermatitis en ratas. En comparación con el estudio realizado también se valoraron los efectos terapéuticos de la aplicación local, la cual es una buena alternativa en lugar o complementada con métodos tradicionales en el tratamiento de dermatitis.

En una investigación realizada por los autores (Liu \& Otros, 2006) estos pudieron comprobar que cabras que tenían una enfermedad conocida como ectima contagioso tras la aplicación de aceite ozonizado por 20 días en forma tópica se curaron completamente de las lesiones. Esto coincide con el estudio que se ha realizado en cuanto a que la terapia de ozono es un tratamiento eficaz contra problemas dermatológicos al cabo de 20 días de tratamiento.

En la tesis publicada por (Bernal, 2014) se demostró que la ozonoterapia es una alternativa para el tratamiento de la dermatitis bacteriana, estudiodonde hubo un buen resultado en la disminución de las cargas bacterianas después de la aplicación de 4 a 8 días en forma tópica. Nuestro estudio concuerda con esta investigación.

\section{Conclusiones}

Se encontró que el porcentaje de bacterias causantes de las dermatopatías fueron Staphyloccous spp 26.66\%, Staphylococcus epidermidis $33.33 \%$, Proteus spp $13.33 \%$, Escherichia coli $3.33 \%$, Staphylococcus aureus $3.33 \%$, Klebsiella $3.33 \%$, Enterococcus $3.33 \%$.

Los ácaros estuvieron distribuidos en un $96 \%$ de los casos, los cuales fueron ocasionados por Demodex canis y un $4 \%$ por Sarcoptes scabiei.

Las dermatopatías mixtas afectaron a un $77 \%$ de los casos y el resto fueron producidas por bacterias.

Las dermatopatías fueron clasificadas en superficiales y profundas y se encontró que las dermatopatías mixtas y superficiales se presentaron en un $82,6 \%$ y las profundas un $17,39 \%$. El $100 \%$ de las dermopatías bacterianas fueron superficiales. 
Se realizó el tratamiento mediante la ozonoterapia por aplicación tópica en 7 pacientes, lo que representó el 23\%. La tolerancia de este esquema en general fue buena en un $96 \%$.

La ozonización por inmersión se realizó por baños de inmersión y fue tolerable en todos los casos, se la realizó en el 17\% de los casos.

Durante la ozonización por bolsa se debió rodear la o las superficies a tratar y se procedió a insuflar dentro de la bolsa el ozono.se realizó en el 10\% de los casos y hubo un caso en el que su tolerancia no fue muy buena, representando un $3 \%$.

Se encontró que en el $20 \%$ de las dermatopatías mixtas se realizó tratamiento tópico, el 3,3\% se trató por medio de bolsa, $10 \%$ por inmersión y un $43,3 \%$, fue a través de una ozonización mixta.

En las dermatopatías bacterianas el método de aplicación fue en un $57,1 \%$ fue tópico, un $14,2 \%$ por medio de bolsa, un 14,2\% por inmersión y el $14,2 \%$ fue tratado a través de ozonización mixta.

Se relacionaron los grupos menores de un año y mayores de un año, y se encontró que en un 43,5\% los caninos afectados fueron menores de un año. Un 56,5\% de los casos fueron mayores de esta edad. Se encontró que en el grupo de cachorros las dermatopatías eran en un $6,6 \%$, de origen bacteriano y $36,6 \%$ mixtas.

Se distribuyó la muestra en hembras y machos, y se encontró que un $39,9 \%$ fueron hembras y un 59,9\% machos .

Un $33 \%$ de los casos fueron perros de pelo largo y un $67 \%$ de pelo corto.

Como promedio, los pacientes acudieron a los 21 días de su control después de la inclusión en el estudio y el 100\% de los pacientes (30) utilizaron ozonoterapia en baños de la forma planteada, es decir, en baños de inmersión, bolsa plástica o forma tópica.

Ninguno de los pacientes tuvo intenciones de dejar el tratamiento, al menos en los días que se realizó.

La ozonoterapia en el tratamiento de las dermatopatias, aplicada por gasificación externa, es efectiva para el tratamiento de dermatopatías de origen bacteriano. Al ser una técnica que disminuye costos de administración de antibióticos se la recomendaría como terapia para el control de este tipo de dermatopatías. Se ha demostrado excelente tolerancia y además tiene aceptación por parte del dueño de la mascota, esto en función de los resultados que se obtuvieron en un corto plazo y con resultados evidentes.

Gracias a los resultados, al final de este estudio se concluye que la ozonoterapia puede ser utilizada, amplia y cotidianamente en el tratamiento de las dermatopatías generalizadas en perros, demostrando excelente tolerabilidad y además aceptación de los resultados obtenidos. 


\section{Recomendaciones}

Se debe considerar a la ozonoterapia como una técnica innovadora de primera elección en el manejo de las dermatopatías generalizadas. Funciona además como un excelente coadyuvante en los tratamientos etiológicos de las dermatopatías por su efecto antiinflamatorio, antibacterial y antifúngico, pudiéndose evidenciar los resultados en un corto tiempo de entre 7 hasta 21 días promedio. No desencadena efectos colaterales ni toxicidad eligiendo una técnica adecuada de aplicación posterior a una correcta evaluación clínica.

El tratamiento de ozonoterapia debe tener un monitoreo frecuente y permanente el cual permite reducir el tiempo de aplicación de ozono sin crear resistencia terapéutica.

En la medicina veterinaria este debe ser implementado como alternativa terapéutica por todos los beneficios antes mencionados.

\section{References:}

1. Balazs, V. (2012). PIODERMA EN EL CANINO. Recuperado el 03 de 12 de 2016, de Redvet: file:///F:/Tesis\%20de\%20Ozono/piodermas.pdf

2. Donner, A. \& Kenner, K. (2011). "Investigation of In Package Ozonation “. \{Recuperado el 30 de 08 de 2016\}, disponible research: http://docs.lib.purdue.edu/cgi/viewcontent.cgi?article=1004\&context $=$ jpur

3. Fogel, F. \& Manzuc, P. (2009). Dermatología canina para la práctica clínica diaria. Buenos Aires: Inter- Médica.

4. Hand, E. (30 de junio de 2016). Ozone layer on the mend, thanks to chemical ban. Recuperado el 24 de 08 de 2016, de science: http://www.sciencemag.org/news/2016/06/ozone-layer-mend-thankschemical-ban

5. IOA (2016). International Ozone Association. Recuperado el 26 de 08 de 2016, de OZONE: file:///F:/Tesis\%20de\%20Ozono/ozone.pdf

6. Jiménez, M. (2010). (29 de junio de 2010 \{Recuperado el 27 de 08 de 2016\}, de Ozono: Gas de la vida: http://www.juventudrebelde.cu/cuba/2010-06-29/ozono-gas-de-lavida/

7. Machicote, G. (2011). Dermatologia canina y felina. Zaragoza: Servet.

8. Martínez, G., Al-Dalain, S., Menéndez, S., Re, L., Giuliani, A., Candelario, E., \& Otros. (31 de octubre de 2005). http://www.sciencedirect.com. Recuperado el 10 de noviembre de 2016, de Therapeutic efficacy of ozone in patients with diabetic foot: http://www.sciencedirect.com/science/article/pii/S001429990500787 9 
9. Martínez Sánchez, G., Re, L., Pérez Davison, G., \& Horwat, R. (2012). “Las aplicaciones médicas de los aceites ozonizados, actualización”. \{Recuperado el 30 de 08 de 2016\}, de dialnet.unirioja.e: file:///C:/Users/user/Downloads/DialnetLasAplicacionesMedicasDeLosAceitesOzonizados-3915879.pdf

10. Medleau, L. \& Hnilica, K. (2007). Dermatología de pequeños animales. Madrid: Elsevier.

11. Pacheco Albán, A. (2012). Utilización de una crema a base de ozono para la otitis externa canina en el barrio La Ecuatoriana en la ciudad de Quito. Recuperado el 30 de 08 de 2016, de http://repositorio.utc.edu.ec/: http://repositorio.utc.edu.ec/bitstream/27000/857/1/T-UTC-1201.pdf

12. Ramírez, A. (2015). Recuperado el 29 de 08 de 2016, de Aplicación de Ozono-Terapia en Pacientes con: https://digitum.um.es/xmlui/bitstream/10201/45768/1/Ana\%20M\%C 2\%AA\%20Ram\%C3\%ADrez\%20Pe\%C3\%B1a\%20-\%20Tesis.pdf

13. Según Scwhartz, A. \& Martínez Sánchez, G. (2012). La ozonoterapia y su fundamentación científica. Recuperado el 29 de 08 de 2016, de dialnet.unirioja.es: file://C:/Users/user/Downloads/Dialnet LaOzonoterapiaYSuFundamentacionCientifica-3915917\%20(1).pdf

14. tecnozono.com. (24 de agosto de 2015). Ozono. Recuperado el 27 de 08 de 2016, de Tecnozono: http://www.tecnozono.com/ozono.htm

15. www.un.org. Protocolo de Montreal relativo a las sustancias que agotan la capa de ozono. (marzo de 2000 \{ Recuperado el 25 de 08 de 2016\}, www.unep.org/ozone:http://www.mma.gob.c1/1304/articles49410_Pr otocolo_Montreal.pdf 